\title{
Pregnant rat uterus expresses high levels of the type 3 iodothyronine deiodinase
}

\author{
Valerie Anne Galton, Elena Martinez, Arturo Hernandez, Emily A. St. Germain, \\ Joanne M. Bates, and Donald L. St. Germain
}

Departments of Physiology and Medicine, Dartmouth Medical School, Lebanon, New Hampshire 03756, USA

Address correspondence to: Donald L. St. Germain, Dartmouth Medical School, One Medical Center Drive, Lebanon, New Hampshire 03756, USA. Phone: (603) 650-7910; Fax: (603) 650-6130; E-mail: stgermain@dartmouth.edu

Received for publication December 16, 1998, and accepted in revised form February 25, 1999.

\begin{abstract}
Although thyroid hormones are critically important for the coordination of morphogenic processes in the fetus and neonate, premature exposure of the embryo to levels of the hormones present in the adult is detrimental and can result in growth retardation, malformations, and even death. We report here that the pregnant rat uterus expresses extremely high levels of the type 3 iodothyronine deiodinase (D3), which inactivates thyroxine and 3,3',5-triiodothyronine by 5 -deiodination. Both D3 mRNA and activity were present at the implantation site as early as gestational day 9 (E9), when expression was localized using in situ hybridization to uterine mesometrial and antimesometrial decidual tissue. At later stages of gestation, uterine D3 activity remained very high, and the levels exceeded those observed in the placenta and in fetal tissues. After days E12 and E13, as decidual tissues regressed, D3 expression became localized to the epithelial cells lining the recanalized uterine lumen that surrounds the fetal cavity. These findings strongly suggest that the pregnant uterus, in addition to the placenta, plays a critical role in determining the level of exposure of the fetus to maternal thyroid hormones.
\end{abstract}

J. Clin. Invest. 103:979-987 (1999).

\section{Introduction}

Thyroid hormones are essential for normal development in vertebrate species (1). In humans, this is most evident in the central nervous system, where thyroid hormone deficiency during the fetal and neonatal periods results in congenital hypothyroidism, which is characterized by irreversible deafness, ataxia, and mental retardation (2). However, the levels of thyroid hormones required for development and the timing of their appearance are critical; exposure of the embryo to excessive levels of these compounds is highly detrimental. In mammals, this can result in fetal malformations, growth retardation, craniosynostosis, and abnormal brain development that is manifested by learning disabilities and mental retardation (3-8). In amphibia, premature exposure to exogenous thyroid hormones results in uncoordinated development that inevitably results in larval death (9).

It is notable that the plasma and tissue levels of the active thyroid hormones thyroxine $\left(\mathrm{T}_{4}\right)$ and 3,3',5-triiodothyronine $\left(T_{3}\right)$ are much lower in the mammalian fetus than in the mother during most of gestation (10). This is partly due to the fact that the fetal thyroid gland does not become functional until the mid-developmental period and remains relatively inactive until birth (11), but the primary reason is that only minimal amounts of maternal $\mathrm{T}_{4}$ and $\mathrm{T}_{3}$ are transferred to the fetus. This has been attributed to the expression in the fetus and placenta of the type 3 iodothyronine deiodinase (D3), which converts $T_{4}$ and $T_{3}$ by 5 -deiodination to the inactive metabolites $3,3^{\prime}, 5^{\prime}$-triiodothyronine (reverse $\mathrm{T}_{3}$ ) and $3,3^{\prime}$ diiodothyronine, respectively (12). The high levels of D3 expression in the placenta have clearly been demonstrated to limit transfer of maternal circulating thyroid hor- mones to the fetus (13). However, thyroid hormones are small, diffusible lipophilic compounds, and they should be able to reach the fetus through the surrounding maternal uterus. That this apparently does not occur to any measurable extent suggests that the uterus may also play an important role in regulating thyroid hormone access to the developing fetus either before placental function, which begins in the rat on gestational day 11 (E11) (14), or during the later stages of pregnancy.

The present study was carried out to investigate this possibility. Our data reveal that D3 is expressed in the pregnant uterus at extremely high levels that exceed that previously demonstrated in any other mammalian tissue, including the placenta.

\section{Methods}

Animals. Timed-pregnant rats (12-14 weeks old) were purchased from Charles River Laboratory Inc. (North Wilmington, Massachusetts, USA). Rats were housed under conditions of controlled lighting and temperature until they were sacrificed for study between days E9 and E21. Virgin female rats of comparable age were purchased from the same supplier to provide data in the nonpregnant uterus. All animal protocols were approved by the Institutional Review Board of Dartmouth Medical School.

Determination of 5-deiodinase activity. Rats were sacrificed by decapitation and exsanguination. The uterus, along with its contents, was rapidly removed and dissected free of the surrounding adipose tissue. It was then cross-sectioned to separate the individual implantation sites. At days E9 and E11, no further dissection was carried out. At days E13-E21, the implantation site was opened by making a longitudinal cut along the antimesometrial side of the uterine wall. This part of the uterus lies directly over the dorsal side of the fetus and 


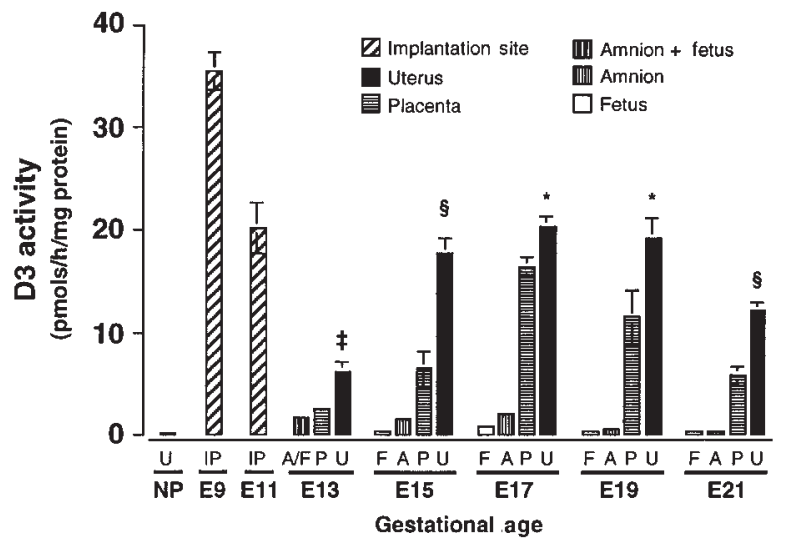

Figure 1

Type 3 iodothyronine deiodinase (D3) activity in the implantation site, uterus, placenta, fetus, and amnion at different stages of gestation in the rat. All values represent the mean $\pm \mathrm{SE}$ of four samples harvested from the same pregnant dam at each gestational age. ${ }^{*} P<0.05, \ddagger P<0.01, \S P$ $<0.001$ uterus vs. placenta. $A$, amnion; $A / F$, amnion plus fetus; $F$, fetus; $I P$, implantation site; $N P$, nonpregnant; $P$, placenta; $U$, uterus.

is on the opposite side of the fetus from the attachment site of the placenta. The uterus was folded back over the amniotic sac containing the fetus and the placenta, and was then gently peeled free from these tissues. The amniotic sac, fetus, and placenta were then separated from each other. The following tissues or combinations of tissues were obtained: at E9 and E11, whole implantation site; at E13, fetus plus amnion, placenta, uterus; and at E15-E21, fetus, amnion, placenta, uterus. At some stages, the fetus was separated into head and trunk for separate analysis, or samples of fetal liver, intestine, skin, and hindlimb were obtained.

Tissues were homogenized in $0.25 \mathrm{mM}$ sucrose, $20 \mathrm{mM}$ Tris$\mathrm{HCl}$ ( $\mathrm{pH}$ 7.6), as described previously (15), using a Tissumizer (Tekmar Co., Cincinnati, Ohio, USA) and sufficient buffer to yield approximately a 1:5 homogenate (wt/vol). The homogenates were centrifuged at $1,000 \mathrm{~g}$ for $15 \mathrm{~min}$ and the supernatants stored at $-20^{\circ} \mathrm{C}$ for subsequent assay of 5-deiodinase activity, according to our published method (16). The reaction mixture (total volume: $50 \mu \mathrm{l}$ ) contained between 1 and $250 \mu \mathrm{g}$ of tissue protein and was adjusted to ensure that deiodination was less than $20 \%$. The assay incubation time was $1 \mathrm{~h}$, and $\left.1 \mathrm{nM} 3^{\prime}-{ }^{125} \mathrm{I}\right] \mathrm{T}_{3}$ was used as substrate with $50 \mathrm{mM}$ DTT as cofactor. Activity is expressed as picomoles of $\mathrm{T}_{2}$ generated per hour per milligram of protein. $\left[{ }^{125} \mathrm{I}\right] \mathrm{T}_{3}(\sim 2,200 \mathrm{Ci} / \mathrm{mmol})$ was obtained from Dupont de Nemours (Wilmington, Delaware, USA) and was purified by chromatography before use with Sephadex LH-20 (Sigma Chemical Co., St Louis, Missouri, USA). Protein concentrations of all samples were determined according to the method of Comings and Tack (17).

Northern analysis. Total RNA was prepared from various tissues using a commercial RNA isolation reagent (Tri Reagent; Molecular Research Center Inc. Cincinnati, Ohio, USA), according to the manufacturer's instructions. Poly $(\mathrm{A})^{+} \mathrm{RNA}$ was isolated from the total RNA as described previously (18). Northern analysis was carried out as described previously using the NS43-1 rat D3 cDNA as a probe (19). Hybridization was conducted at $42^{\circ} \mathrm{C}$ with final washes at $55^{\circ} \mathrm{C}(18)$.

In situ bybridization. In situ hybridization was performed on whole uterine implantation sites from E9, E12-13, and E15 animals, and on isolated uteri from E17 and E19 animals obtained as described above. After harvesting, the tissues were placed in ice-cold PBS ( $\mathrm{pH} 7.4$ ) containing $4 \%$ paraformaldehyde and incubated at $4^{\circ} \mathrm{C}$ overnight, followed by incubation for $16 \mathrm{~h}$ at $4^{\circ} \mathrm{C}$ in the same solution plus sucrose $(30 \% \mathrm{wt} / \mathrm{vol})$. Tissues were then embedded in OCT compound (Miles Inc., Elkhart, Indiana, USA) frozen in dry ice, and stored at $-70^{\circ} \mathrm{C}$ for subsequent sectioning and analysis.

Tissue sections $(20 \mu \mathrm{m})$ were cut at $-25^{\circ} \mathrm{C}$ in a cryostat, thaw-mounted onto Superfrost slides (Fisher Scientific Co., Pittsburgh, Pennsylvania, USA), and dried at $37^{\circ} \mathrm{C}$ overnight. To improve the accessibility of the probes to the mRNA, the thaw-mounted sections were placed in PBS containing $0.3 \%$ Triton $\mathrm{X}-100$ for $10 \mathrm{~min}$, and then in $0.2 \mathrm{~N} \mathrm{HCl}$ for $10 \mathrm{~min}$. They were then acetylated in $0.1 \mathrm{M}$ triethanolamine containing $0.25 \%$ acetic anhydride for $10 \mathrm{~min}$, postfixed in $4 \%$ paraformaldehyde for $10 \mathrm{~min}$, and dehydrated in a series of ethanol solutions $(30 \%, 50 \%, 70 \%$, and $90 \%)$ for 2 min each, followed by $100 \% \mathrm{EtOH}$ for $10 \mathrm{~s}$. Between each treatment, slides were washed in PBS for $5 \mathrm{~min}$. Slides were air-dried at room temperature.

To aid in demonstrating the specificity of binding, uterine sections in one experiment were treated before the postfixation step with $100 \mu \mathrm{g} / \mathrm{ml}$ of ribonuclease $\mathrm{A}$ in $0.5 \mathrm{M} \mathrm{NaCl}, 50 \mathrm{mM}$ Tris ( $\mathrm{pH} 7.5$ ), and $5.0 \mathrm{mM}$ EDTA for $1 \mathrm{~h}$ at $37^{\circ} \mathrm{C}$. Sections were then washed with PBS, postfixed with $4 \%$ paraformaldehyde as above, and hybridized with the D3 antisense probe.

To prepare the RNA probes, a portion of the coding region (bp 239-831) of the rat D3 cDNA contained in the rNS27-1 clone (19) was excised using SalI and ligated into pBluescript (Stratagene, La Jolla, California, USA). The insert was then amplified by PCR using the T3 and T7 oligonucleotide primers. Radiolabeled antisense and sense RNA probes were synthesized from the PCR product by in vitro transcription using the T3 (for

\section{a}
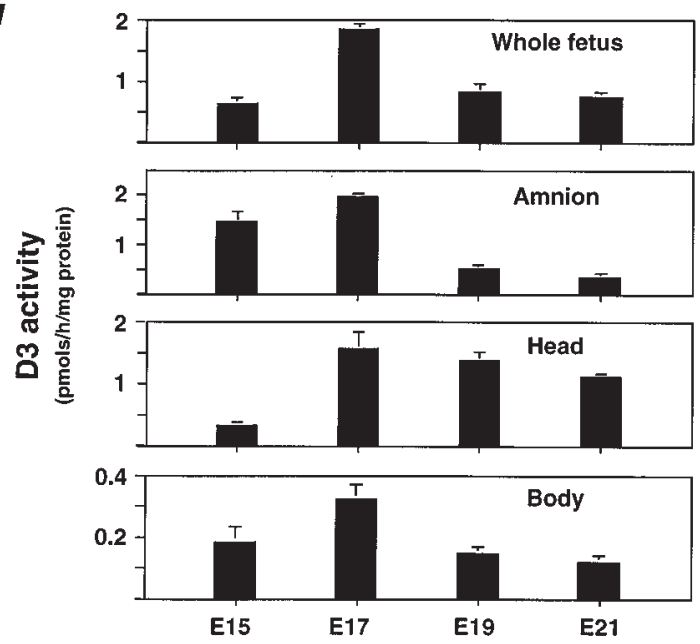

b

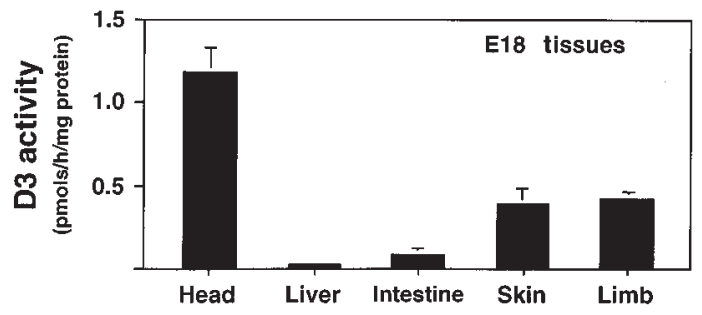

Figure 2

D3 activity in (a) the whole fetus, amnion, head, and body at different stages of gestation, and $(\boldsymbol{b})$ fetal tissues harvested at gestational day 18 (E18). All values represent the mean $\pm \mathrm{SE}$ of four samples harvested from the same pregnant dam at each gestational age. 


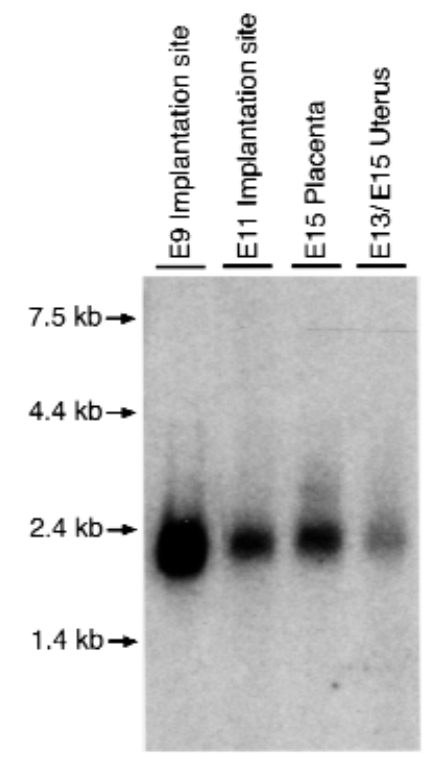

Figure 3

Northern analysis of poly $(A)^{+}$RNA samples prepared from implantation sites obtained at $E 9$ and $E 11$, placenta at E15, and pooled samples of uterus at E13 and E15. Samples were probed with a rat D3 cDNA. The amounts of poly $(A)^{+}$RNA loaded in each lane were 40, 31, 33, and 27 $\mu \mathrm{g}$, respectively, from left to right. After hybridization and washing, the blot was subjected to autoradiography for $20 \mathrm{~h}$.

antisense) or T7 (for sense) polymerase, components from the Maxi-Script kit (Ambion Inc., Austin, Texas, USA), and $\left.{ }^{[35} \mathrm{S}\right] \mathrm{UTP}$. A mouse $\beta$-actin cRNA probe was synthesized from components provided in the same kit. The probes were purified using the $\mathrm{NH}_{4} \mathrm{OAc} /$ ethanol precipitation protocol provided with the Maxi-Script kit.

The hybridization solution contained $50 \%$ formamide, $10 \%$ dextran sulfate, $5 \times$ Denhardt's solution $(1 \times$ Denhardt's solution: $0.02 \%$ BSA, $0.02 \%$ Ficoll 400 , and $0.02 \%$ polyvinylpyrrolidone), $0.62 \mathrm{M} \mathrm{NaCl}, 50 \mathrm{mM}$ DTT, $10 \mathrm{mM}$ EDTA, $20 \mathrm{mM}$ PIPES-Na (pH 6.8), $0.2 \%$ SDS, $250 \mu \mathrm{g} / \mathrm{ml}$ salmon sperm DNA, and $250 \mu \mathrm{g} / \mathrm{ml}$ yeast transfer RNA. The appropriate $\left.{ }^{35} \mathrm{~S}\right] \mathrm{RNA}$ probe, at a final concentration of $2 \times 10^{7} \mathrm{cpm} / \mathrm{ml}$, was added to $0.5 \mathrm{ml}$ of the hybridization buffer, and $20 \mu \mathrm{l}$ of this solution was pipetted onto each slide and a coverslip applied. Slides were incubated in humid chambers at $55^{\circ} \mathrm{C}$ overnight.

After incubation, coverslips were removed by dipping slides into a beaker containing $100 \mathrm{ml}$ of $1 \times \mathrm{SSC}(0.05 \mathrm{M} \mathrm{NaCl}$ and $0.0015 \mathrm{M} \mathrm{Na}$ citrate.) Excess probe was removed by placing slides in $2 \times$ SSC containing $10 \mathrm{mM} \beta$-mercaptoethanol for 30 min, followed by incubation with $4 \mu \mathrm{g} / \mathrm{ml}$ ribonuclease $\mathrm{A}$ in $0.5 \mathrm{M} \mathrm{NaCl}, 50 \mathrm{mM}$ Tris (pH 7.5), and 5.0 mM EDTA for $1 \mathrm{~h}$ at $37^{\circ} \mathrm{C}$. Slides were then washed, first in $0.5 \times \mathrm{SSC}$ containing $50 \%$ formamide and $10 \mathrm{mM} \beta$-mercaptoethanol at $55^{\circ} \mathrm{C}$ for 2 $\mathrm{h}$, and then in $0.1 \times \mathrm{SSC}$ containing $10 \mathrm{mM} \beta$-mercaptoethanol at $68^{\circ} \mathrm{C}$ for $1 \mathrm{~h}$. After a final wash in PBS for $5 \mathrm{~min}$, sections were dehydrated in a series of ethanol solutions $(40 \%, 60 \%$, $80 \%$, and $90 \%$ ) containing $0.3 \mathrm{M} \mathrm{HN}_{4} \mathrm{OAc}$ for $90 \mathrm{~s} \mathrm{each}$, followed by $100 \%$ ethanol for $10 \mathrm{~s}$, and allowed to dry at room temperature. Sections were exposed for 4-5 days to Beta-Max film (Amersham Life Sciences Inc., Arlington Heights, Illinois, USA) and then dipped in LM-1 emulsion (Amersham Life Sciences Inc.). After exposure for 2 weeks at $4^{\circ} \mathrm{C}$, the slides were developed with Kodak D19 developer (Eastman Kodak Co. Scientific Imaging Systems, Rochester, New York, USA), fixed, and counterstained with hematoxylin. Slides were examined using both light-field and dark-field microscopy.

\section{Results}

D3 activity is highly expressed in the uterus, placenta, and fetus during development. D3 activity in the uterus, placenta, amnion, and fetus at different stages of gestation is shown in Figure 1. The highest level of D3 activity observed in any tissue preparation in either this or any previous study from this laboratory was present in the whole implantation site at day E9, where the level exceeded $30 \mathrm{pmol} / \mathrm{h} / \mathrm{mg}$ protein. This value is nearly double the highest values obtained for placental tissue, which were noted on days E15-E19, and is approximately 20-fold greater than the highest level of D3 activity observed in the fetal brain, which occurs on day E17 (vide infra).

D3 activity was also very high in the implantation site at day E11, though the value, when expressed per milligram of protein, was approximately half that noted at day E9. However, given the greater mass of tissue present at day E11, the total amount of D3 activity per implantation site at stages E9 and E11 is probably comparable. At these stages of development, the maternal decidua constitutes by far the greatest mass of tissue present at the implantation site.

By day E13, the implantation site could be dissected so that the uterus, placenta, and the fetus and amnion (as a unit) could be separated from each other. From day E15 onward, the amnion could be taken separately. D3 activity in each of these tissues is shown in Figure 1. The levels of D3 activity in the uterus and placenta were much lower at day E13 than in the whole implantation sites at days E9 and E11. However, as gestation continued, values in these tissues increased to levels that approached those observed in the E11 implantation site. Uterine D3 activity reached a maximum at day E15 and persisted at this level throughout much of the remainder of gestation, whereas placental activity appeared to peak at day E17 and then decline.

Several notable features emerge from these data. First, D3 activity is higher in the uterus than in the placenta throughout gestation. Second, levels of D3 activity in these two tissues are at least 10 times higher than those in the fetus itself. Third, considerable D3 activity is present in the amnion. Fourth, the increase in uterine D3 activity that occurs during pregnancy is dramatic and occurs early during gestation; in the nonpregnant uterus, D3 activity was $0.114 \pm 0.018( \pm \mathrm{SE}) \mathrm{pmol} / \mathrm{h} / \mathrm{mg}$ protein, and thus the values observed in the E9 and E11 implantation sites, and later in the isolated uterus, represent 200- to 300-fold increases in the levels of expression.

Although lower than in the uterus and placenta, considerable amounts of D3 activity were present in both the fetus and the amnion (Figure $2 a$ ); and before day E17, activity was higher in the amnion than in the whole fetus. As was the case in the isolated uterus and placenta, maximum D3 activity in the amnion and fetus occurred at day E17. The major fraction of the D3 activity in the fetus was present in the head, but significant activity was also found in the body, notably in skin, limb, and intestine (Figure 2b). Although D3 activity was also detectable in fetal liver, levels in this tissue at all stages studied were much lower than in other organs.

A 2.2-kb D3 $m R N A$ is expressed in the pregnant rat uterus: Northern analysis of poly (A) ${ }^{+}$RNA prepared from the 

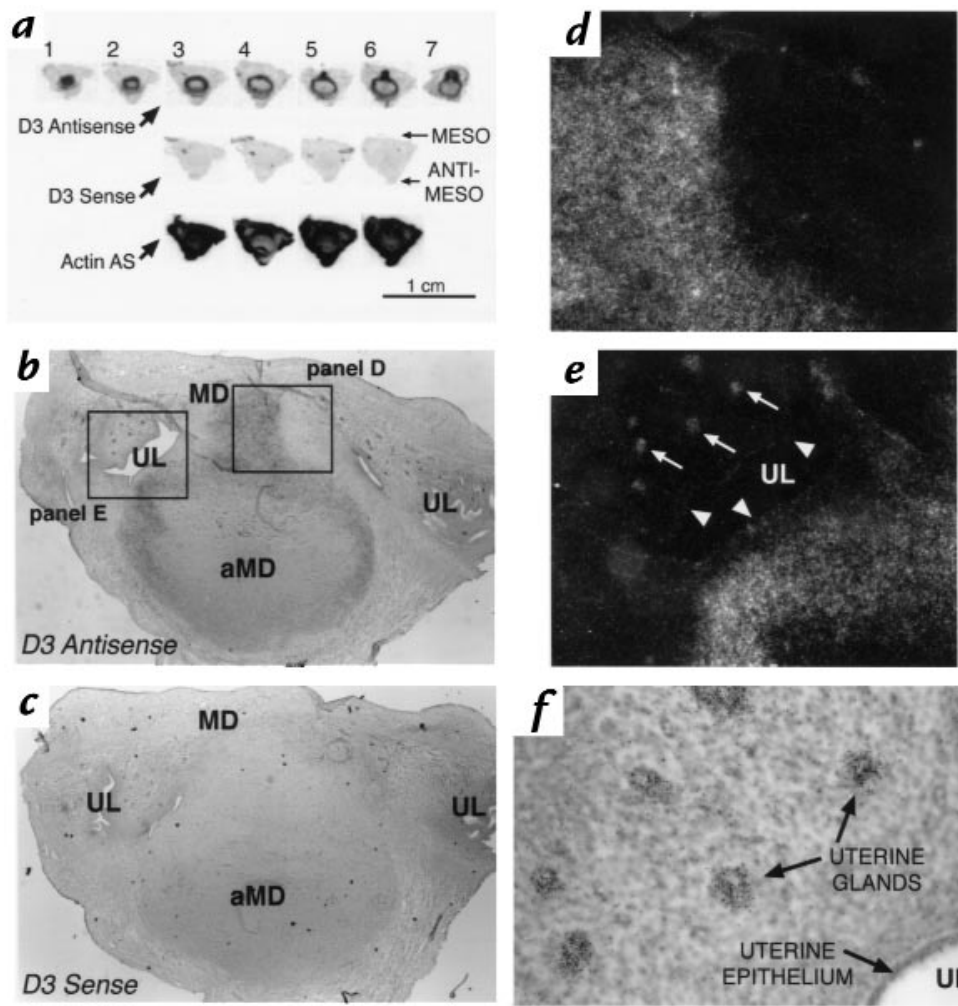

\section{Figure 4}

In situ hybridization using D3 antisense, sense, or actin antisense probes on sections of a uterine implantation site on day E9. (a) Composite autoradiograph of adjacent longitudinal sections hybridized with the probes indicated. Section 1 represents the most peripheral section, whereas section 7 is through the midportion near the implantation site. Sections are oriented so that the mesometrial surface of the uterus is toward the top. (b) Photomicrograph of section 6 probed with the D3 antisense probe. Darker portions indicate the location of silver grains deposited by the photographic emulsion at the sites of D3 antisense probe hybridization. Boxes indicate the regions viewed under higher magnification in $d$ and $e$. (c) Photomicrograph of a section adjacent to that shown in $b$ probed with the D3 sense probe. (d) Dark-field photomicrograph of the mesometrial decidual region from the section in $b$. White dots represent light scatter from the silver grains deposited at the sites of D3 antisense probe hybridization. (e) Dark-field photomicrograph of the decidual region abutting the uterine lumen from the section in $b$. Arrows point to silver grains specifically deposited over the uterine glands. No signal is apparent in the epithelial cells lining the uterine lumen (arrowheads). ( $f$ ) Higher-powered light-field photomicrograph showing silver grains specifically deposited over the uterine glands in the section shown in $b$ and $e$ and hybridized with the $\mathrm{D} 3$ antisense probe. $a M D$, antimesometrial decidua; $M D$, mesometrial decidua; $U L$, uterine lumen.

implantation sites at days E9 and E11, pooled samples of pregnant uterus from days E13 and E15, and the placenta at day E15, was performed using a rat D3 cDNA as probe. A single RNA species of $2.2 \mathrm{~kb}$ was observed in all four samples (Figure 3). Upon extended exposure, no additional larger bands, comparable to those previously noted in the rat brain (19), were observed (data not shown).

In situ bybridization localizes D3 expression in early gestation to the maternal decidua. Figure 4 shows the results of in situ hybridization performed on a uterine implantation site from a pregnant rat at day E9. A composite autoradiograph of serial longitudinal sections through the uterus is shown in Figure 4a. Sections start at the periphery of the tissue (section 1) and extend approximately halfway through the specimen, almost to the implantation chamber (section 7). All sections are from the same specimen and adjacent sections have been hybridized with either the D3 antisense, D3 sense, or actin antisense probes, as indicated. The sections are oriented so that the mesometrial surface is toward the top of the figure. Hybridization with the D3 antisense probe revealed a spherical pattern of expression in what appeared to be the decidual tissue, with accentuation in the mesometrial component, as seen in sections 5-7. This pattern was markedly different from the generalized pattern of hybridization seen with the actin antisense probe. The D3 sense probe showed no specific hybridization signal. In addition, no signal was noted when sections were treated with ribonuclease A before the hybridization reaction (data not shown).

A low-power photomicrograph of section 6 confirms that D3 mRNA is highly expressed in the antimesometrial and mesometrial decidua at the E9 implantation site (Figure $4 b$ ). For comparison, an adjacent section hybridized with the D3 sense probe is shown in Figure $4 c$. The intensity of the signal in the mesometrial region is demonstrated by the higher-powered dark-field photomicrograph shown in Figure $4 d$.

As shown in Figure $4 b$, the intense hyperplasia of endometrial stromal cells, which occurs during decidualization, obliterates the uterine lumen at the implantation site. However, lateral to the implantation site, the uterine lumen remains patent (20). Figure $4 e$ shows a higher-powered dark-field view of this area. Intense signal is demonstrated in the decidual tissue bordering the lumen, but no significant increase in grain pattern is seen over the epithelial cells lining the cavity (arrowheads). However, localized signal is observed over the uterine glands (arrows). This can also be appreciated in the higher-powered light-field photomicrograph of the same region shown in Figure $4 f$.

At later stages of gestation, D3 is expressed in the uterine luminal epithelial cells. From days E10 to E15 in the rodent, marked structural alterations occur in the uterus at the implantation site $(20,21)$. These include (a) regression of the antimesometrial decidua to form a thin band of tissue, termed the decidual capsularis, which overlies the fetal cavity; (b) incorporation of those portions of the mesometrial decidua invaded by the trophoblast into the placenta, with the remaining uterine tissue in this region forming the decidua basalis; and (c) recanalization of the uterine lumen between the decidual capsularis and the uterine wall so that by day E15 the lumen is again patent throughout the length of this organ (20). The lumen at this point lies on the antimesometrial side of the uterus and abuts the fetal membranes. It is thus located on the opposite side of the fetal cavity and conceptus from the placenta. 

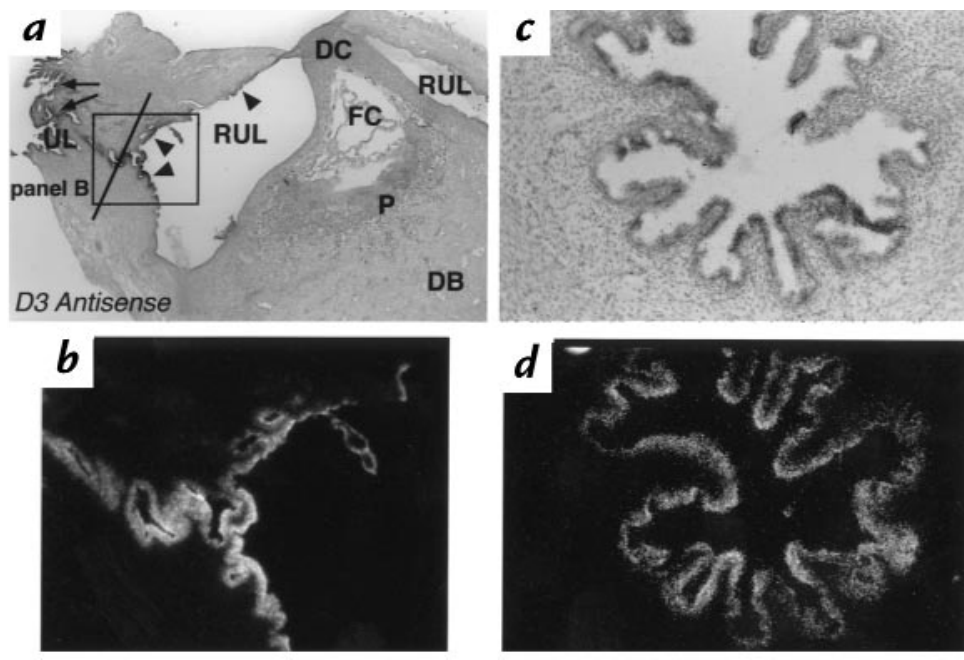

\section{Figure 5}

In situ hybridization using the D3 antisense probe on sections of a uterine implantation site on approximate day E12-E13. (a) Low-powered photomicrograph of a longitudinal section showing the antimesometrial portion of the implantation site. Arrows point to specific signal from the D3 antisense probe that is present in the epithelial cells lining the uterine lumen lateral to the implantation site. Signal is also seen in the epithelial cells lining the recanalized uterine lumen (arrowheads) that abuts the fetal cavity. (b) A higher-power dark-field photomicrograph of the region shown in the box in $a$, demonstrating signal over the epithelial cells lining the uterine lumen. (c) A higher-power light-field photomicrograph, taken from a different specimen, of a cross-section of the uterine lumen in the region of the diagonal line shown in $a$. Silver grains are apparent over the epithelial cells lining the uterine cavity. (d) A dark-field photomicrograph of the same section shown in c. DB, decidual basalis; DC, decidual capsularis; FC, fetal cavity; $P$, placenta; $R U L$, recanalized uterine lumen; $U L$, uterine lumen.

A low-powered photomicrograph of a longitudinal section through a uterine implantation site on day E12-E13 is shown in Figure $5 a$. The section has been subjected to in situ hybridization using the D3 antisense probe. No enhancement of the signal is noted in the regressing decidual capsularis or over the placenta. However, D3 mRNA expression is now apparent in the cells lining the uterine lumen, both lateral to the implantation site (arrows) and in the recanalizing portion (arrowheads) that is progressing to surround the fetal cavity. The dark-field photomicrograph of this region (Figure $5 b$ ) confirms the high intensity of this signal that appears to be confined to the epithelial cells lining the uterine cavity. A crosssection of the uterine lumen (at the point indicated by the diagonal line in Figure 5a) is shown in Figure 5, $c$ and $d$. This again reveals an intense pattern of grains over the epithelial cells. An adjacent section hybridized with the D3 sense probe demonstrated no specific signal in this region (data not shown).

The spatial expression pattern of the D3 in the E15 uterus is shown in Figure 6. Autoradiographs of adjacent sections hybridized with the D3 antisense and sense probes are shown, again oriented so that the mesometrial surface is at the top of the figure. A band of signal (arrowheads) along the wall of the uterine lumen adjacent to the fetal cavity is noted (Figure $6 a$ ). The photomicrographs shown in Figure 6, $b$ and $c$, demonstrate the intensity of the signal in this area. No specific signal is noted in a similar region of an adjacent section probed with the D3 sense probe (Figure $6 d$ ).

As demonstrated in Figure 1, D3 continues to be highly expressed in the uterus during the later stages of gestation. To investigate the spatial pattern of this expression, in situ hybridization was performed on an isolated uterine specimen from day E19. Dissection of the uterus and removal of the fetus, the fetal membranes, and the placenta was performed as described in the Methods section. Using this harvesting procedure, the uterus is turned inside out as it is folded back to remove its contents. As a result, the epithelial cells lining the uterine cavity appear on the outer edges of the specimen. Figure $7 a$ shows an autoradiograph of adjacent cross-sections of an isolated uterine specimen that have been probed with the D3 antisense or sense probes or with an actin antisense probe. A specific circumferential signal is apparent with the D3 antisense probe. Photomicrographs of this region from the D3 antisense- and sense-probed specimens are shown in Figure 7,b and $c$, respectively. Intense signal is again demonstrated over the epithelial cells, which in the native state line the uterine lumen that overlies the fetal cavity. A diagram showing the region from which these sections were taken is shown in Figure $7 d$. Analogous results were obtained with isolated uterine specimens from pregnant rats on day E17 (data not shown).

\section{Discussion}

To our knowledge, the present study is the first to demonstrate that the pregnant rodent uterus expresses extremely high levels of D3 mRNA and activity; that this expression is present early in gestation before placental development; that it continues until the time of parturition; and that it occurs in remarkably different spatial patterns, depending on the gestational age. Previous studies, both in this and other laboratories, have demonstrated the expression of D3 activity by the mammalian placenta and fetus (22-29). Our current findings are consistent with, and extend, these earlier studies. Notably, the levels of D3 activity in the pregnant uterus are even higher than those in the placenta determined at the same stage of gestation and are much higher than those in either the whole fetus or in individual fetal organs. These findings strongly suggest that the pregnant uterus plays a critical role in determining the level of exposure of the fetus to maternal thyroid hormones.

Considerable evidence suggests that a principal function of thyroid hormones during development is as an activator of differentiation programs in multiple tissues (30-44). For example, in the central nervous system, thyroid hormone deficiency results in a generalized delay in brain growth, while thyroid hormone excess accelerates neurogenic development $(2,3,43)$. In both cases, the orderly progression of neuronal maturation through stages of proliferation, migration, differentiation, neurite outgrowth, synaptogenesis, and myelination is disrupted, with profound and irreversible consequences with respect to function. 

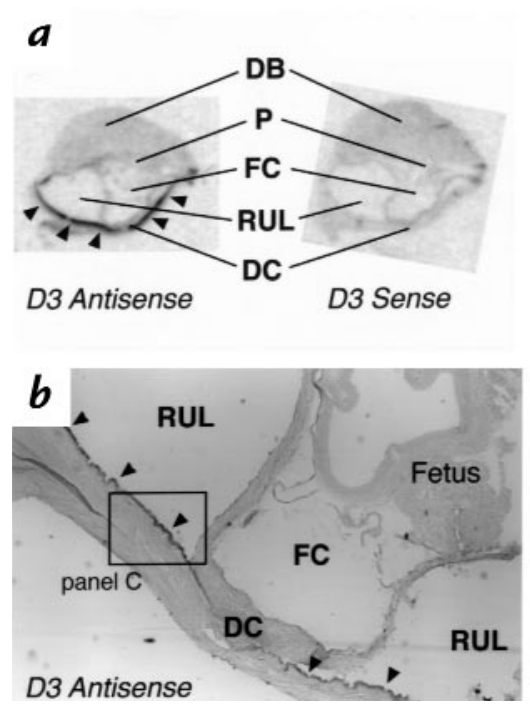

Figure 6

In situ hybridization using the D3 antisense or sense probe on sections of a uterine implantation site on day E15. (a) Composite autoradiograph of adjacent longitudinal sections hybridized with the probes indicated. Sections are oriented so that the mesometrial surface of the uterus is toward the top. Specific signal is observed along the wall of the recanalized uterine lumen (arrowheads). (b) Low-powered and (c) higher-powered photomicrographs showing the antimesometrial portion of the section in a probed with the D3 antisense probe. Silver grains are noted over the epithelial cells lining the outer wall of the recanalized uterine lumen. In contrast, no specific signal is observed in the section hybridized with the D3 sense probe $(\boldsymbol{d})$. $D B$, decidual basalis; $D C$, decidual capsularis; $F C$, fetal cavity; $P$, placenta; $R U L$, recanalized uterine lumen.

Because the rat is relatively immature at birth, many of the most important effects of thyroid hormone on developmental processes occur in the immediate postnatal period. This appears to be particularly true with regard to the differentiation of higher neural centers such as the cerebrum and cerebellum $(4,5)$. Indeed, in a recent report, Schwartz et al. (45) were unable to demonstrate any structural or biochemical effects on the cerebellum of hypo- or hyperthyroidism induced during the late fetal period in the rat.

However, in other areas of the brain, thyroid hormones have clearly been shown to have important influences on developmental processes during embryonic life. Thus, as early as day E9, the thyroid status of the fetus has been demonstrated to have important effects on the proliferation and differentiation of neurons in the motor and mesencephalic nuclei of the trigeminal nerve (46). These regions of the central nervous system are formed and undergo maturation early in development, with neuronal proliferation normally complete by day E12 (47). Thyroid hormone also clearly influences the developmental and/or metabolic function of other fetal organs, including the liver (37) and the heart (30). Furthermore, using whole rat embryo cultures of concepti removed at day E9, high concentrations of $\mathrm{T} 3$ have been demonstrated to be dysmorphogenic and to induce structural abnormalities in cephalic and brachial arches (48).

Based on in situ hybridization techniques, thyroid hormone $\alpha$-receptor mRNA has been demonstrated in the neural tube of the rat fetus at day E11.5, the earliest stage examined so far (49). Expression of this isoform appears to be widespread in the brain by E12.5 (49). A recent report by Nagasawa et al. (50) suggests that thyroid hormone receptors may be expressed at even earlier stages. Using a transgenic mouse model in which $\beta$-galactosidase expression is placed under the control of a portion of the thyroid hormone $\beta 1$-receptor promoter, these investigators detected expression of this marker enzyme in the midbrain and auditory vesicles of mice on day E9.5.

Taken as a whole, these studies suggest that some rodent tissues express thyroid hormone receptors early in gestation and are capable of responding to circulating fetal thyroid hormone levels. It thus appears likely that the high levels of D3 activity expressed in the pregnant uterus, placenta, and fetus serve to limit the premature exposure of proliferating fetal tissues to the differentiating effects of thyroid hormones. In effect, this pattern of D3 expression allows the maternal and fetal thyroid axes to function relatively independently of each other. Fetal thyroid hormone levels can thus be regulated primarily by fetal developmental programs, whereas the maternal thyroid axis can respond to the unique needs of the pregnant mother $(51,52)$.

D3 expression clearly begins very early during gestation. The highest activity levels in this study were observed at the implantation site on day E9, the earliest time point sampled, and just three days after implantation. Given the long residency time of thyroid hormones in tissues $(53,54)$, this pattern of very early uterine expression may help ensure that a thyroid hormone-deficient state in the fetus and surrounding tissues is achieved very early in embryogenesis, so that $T_{3}$ levels are low at the time fetal thyroid hormone receptors are expressed and the placenta becomes functional (E11).

D3 mRNA expression on day E9 is readily detected by Northern analysis, and it is localized by in situ hybridization to both the antimesometrial and mesometrial decidua in such a way that the implantation site is surrounded by D3 expressing tissue. Uterine decidualization is triggered by implantation of the blastocyst and involves the marked proliferation and differentiation of endometrial stromal cells to form an implantation chamber that surrounds the blastocyst (55). The importance of this process has recently been demonstrated in mice genetically altered so that they fail to express functional receptors for the cytokine interleukin-11. Homozygous female mice bearing this defect are infertile because of an inadequate decidualization response that results in death and resorption of the implanted embryo $(56,57)$.

Before and during the early stages of placental development, maternal decidual tissue may serve several critical roles in both rodents and human development. These include the provision of nutritional support for the embryo, limiting the extent to which trophoblastic tissue invades the uterine wall, and regulating the local 
maternal immune response to the implanting blastocyst $(58,59)$. The present study suggests yet another important role for this tissue, namely the inactivation of maternal thyroid hormones during the early stages of embryogenesis. This may be of particular importance given that the increased vascularity and vascular permeability of the decidual tissue (21), would otherwise allow ready access of thyroid hormones to the embryo. Of interest is the possibility that the D3 might serve an important role in pregnant uterine tissue that is independent of its deiodinating activity. For example, other selenoproteins (e.g., glutathione peroxidase) act as antioxidants and serve to protect tissues from toxic environmental chemicals $(60,61)$. To date, however, no such properties of the D3 have been reported.

The shift of D3 expression from decidual tissue in early gestation to the epithelial cells lining the uterine lumen in the latter half of gestation is an intriguing and, as far as we are aware, unique pattern of gene expression in the pregnant uterus. The appearance of D3 mRNA in the uterine epithelium coincides temporally with degeneration and regression of the antimesometrial decidua and with the recanalization of the uterine lumen, so that it comes to reside adjacent to the fetal membranes on the side of the fetal cavity opposite the placenta. This expression in the epithelial cells, in conjunction with the significant levels of D3 activity in the placenta, ensures that the fetal cavity continues to be completely surrounded by tissues expressing high levels of D3 up until the time of parturition. Whereas placental D3 expression has been shown to limit the transfer of circulating maternal thyroid hormones (13), the presence of this enzyme initially in the decidua, and later in uterine epithelial cells, may prevent the entry of these compounds into the fetal cavity from the surrounding uterus. The expression of significant levels of D3 activity in the amnion may serve a similar purpose.

This hypothesis concerning the important role of the uterus, amnion, and placenta in limiting the passage of maternal thyroid hormone to the fetus does not negate the fact that in some species, including human and rodent, small but significant amounts of these hormones are apparently transferred to the fetus and may be important to its development, especially in the setting of impaired fetal thyroid function (62-65). Indeed, both $T_{4}$ and $T_{3}$ have been detected in the rat (66) and human fetus (67) before the onset of fetal thyroid gland function and in athyreotic human infants at term (64). Nevertheless, the uteroplacental unit, primarily because of its high level of D3 expression, does represent a formidable barrier to the passage of maternal thyroid hormone, as evidenced by the significant concentration gradients of $\mathrm{T}_{4}$ and $\mathrm{T}_{3}$ between the maternal and fetal circulations throughout most of gestation and the high fetal $\mathrm{rT}_{3}$ plasma concentration (11).

Our observation that D3 is expressed in the uterine glands on day E9 is of considerable interest. Velardo et al. (68) have demonstrated that epithelial cell proliferation during the recanalization process begins in the uterine glands. Thus, the presence of D3 in these structures early in gestation may be a harbinger of the later expression of this enzyme in the epithelia.

The levels of D3 activity present in the uterus and placenta between E15 and E21 were extremely high and at least 10-fold higher than those found in fetal tissues at these stages. At all stages examined, fetal D3 activity was
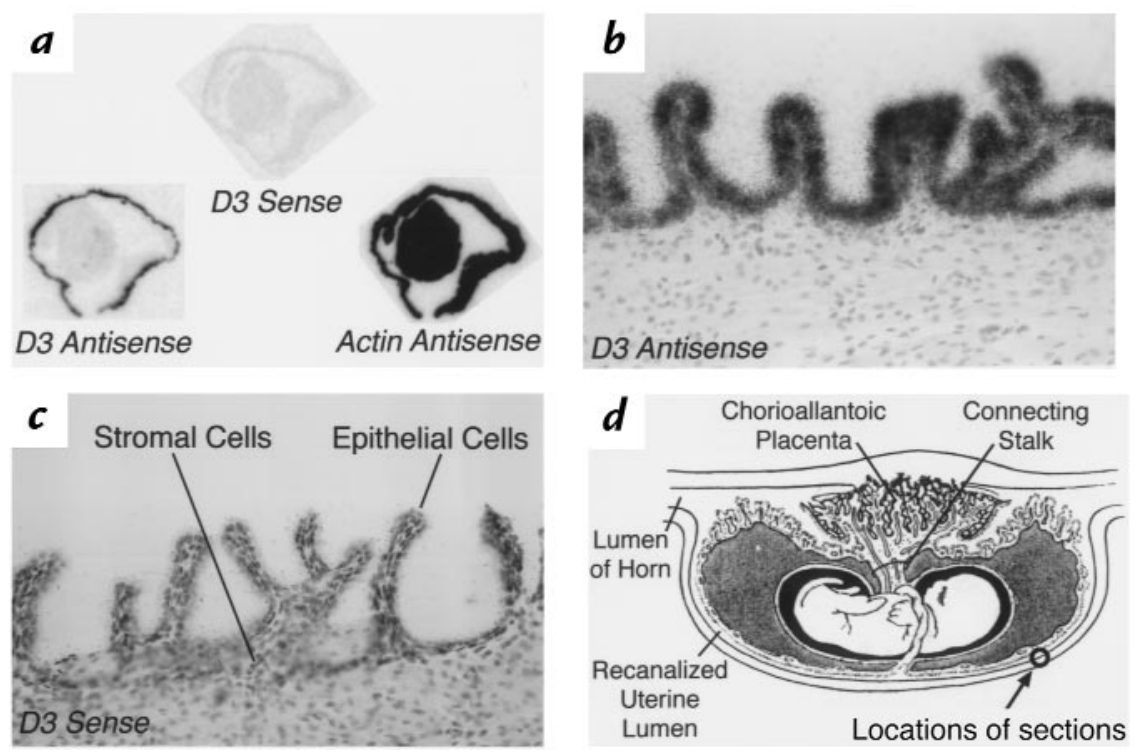

Figure 7

In situ hybridization using D3 antisense, sense, or actin antisense probes on sections of an isolated pregnant uterus from E19. The specimen was harvested (as described in Methods) so that that the epithelial cells lining the recanalized uterine lumen lie on the outside of the specimen. (a) Composite autoradiograph of adjacent sections hybridized with the probes indicated. Specific signal with the D3 antisense probe is observed over the outer edges of the specimen. (b) High-powered light-field photomicrograph of a section hybridized with the D3 antisense probe showing intense signal over the epithelial cells. (c) Hybridization of an adjacent section with the D3 sense probe results in no specific signal. (d) Diagram of a longitudinal section through the fetal cavity and uterus of a late-stage rodent pregnancy, illustrating the approximate locations of the sections in this figure (reproduced, with permission, from ref. 74). 
highest in the head, though substantial amounts of activity were also present in the body, principally in the limbs, skin, and intestine. Such an expression pattern may allow for tissue-specific regulation of thyroid hormone metabolism during fetal development, as has been demonstrated to be important during amphibian metamorphosis (15).

Our in situ hybridization study failed to demonstrate any definite enhancement of the D3 antisense signal in the placenta, despite the fact that high levels of D3 activity are present in placental homogenates and that D3 transcripts are readily detected by Northern analysis in placental RNA samples. Similarly, no specific signal was noted in the fetus, though a comprehensive analysis of fetal expression was not undertaken in this study. We presume that this reflects the fact that D3 mRNA levels in these tissues are either too low or are expressed in such a diffuse pattern that an increase in signal over individual cells cannot be distinguished from background levels. In contrast, D3 expression is markedly elevated in the pregnant uterus and is highly localized, initially in decidual cells and later in the single cell layer of the epithelium.

The factors regulating the expression of D3 during development remain undefined. Of interest, however, is the observation that in certain cell culture systems, such as primary cultures of rat neonatal astroglial cells or differentiating brown adipocytes, D3 mRNA and activity are highly induced by epidermal growth factor, fibroblast growth factor, $T_{3}$, and retinoids (69-73). Given that these agents are known to be present and to play important roles in the processes of decidualization, placentation, and fetal development, it is conceivable that they may be responsible, in part, for the stimulation of D3 activity observed in these tissues. The answer to this question, as well as the role of uterine D3 expression during human pregnancy, requires additional investigation.

\section{Acknowledgments}

The authors wish to thank Juan Bernal, Vince Memoli, and Kenneth Orndorff for their expert advice. We also acknowledge the excellent technical support of David Lori. This study was supported by National Institutes of Health grants HD-09020 (to V.A. Galton) and DK-42271 (to D.L. St. Germain).

1. Schwartz, H.L. 1983. Effect of thyroid hormone on growth and devel opment. In Molecular basis of thyroid hormone action. J.H. Oppenheimer and H.H. Samuels, editors. Academic Press. New York, NY. 413-444.

2. Porterfield, S.P., and Hendrich, C.E. 1993. The role of thyroid hormones in prenatal and neonatal neurological development - current perspectives. Endocr. Rev. 14:94-106.

3. Pasquini, J.M., and Adamo, A.M. 1994. Thyroid hormones and the central nervous system. Dev. Neurosci. 16:1-8.

4. Nicholson, J.L., and Altman, J. 1972. The effects of early hypo- and hyperthyroidism on the development of rat cerebellar cortex. I. Cell proliferation and differentiation. Brain Res. 44:13-23.

5. Nicholson, J.L., and Altman, J. 1972. The effects of early hypo- and hyperthyroidism on the development of rat cerebellar cortex. II. Synaptogenesis in the molecular layer. Brain Res. 44:25-36

6. Daneman, D., and Howard, N.J. 1980. Neonatal thyrotoxicosis: intellectual impairment and craniosynostosis in later years. J. Pediatr. 97:257-259.

7. Harakawa, S., et al. 1989. Changes of serum thyroid hormone levels induce malformations on early embryogenesis in rats. Acta Endocrinol. 121:739-743.

8. Kopp, P., et al. 1995. Congenital hyperthyroidism caused by a mutation in the thyrotropin-receptor gene. N. Engl.J. Med. 332:150-154.

9. Dodd, M.H.I., and Dodd, J.M. 1976. The biology of metamorphosis. In Physiology of the amphibia. B. Lofts, editor. Academic Press. New York, NY. 467-599.

10. Burrow, G.N., Fisher, D.A., and Larsen, P.R. 1994. Maternal and fetal thy- roid function. N. Engl. J. Med. 331:1072-1078.

11. Fisher, D.A., Dussalt, J.K., Sack, J., and Chopra, I.J. 1977. Ontogenesis of hypothalamic-pituitary-thyroid function in man, sheep and rat. Recent Prog. Horm. Res. 33:59-78.

12. St. Germain, D.L. 1994. Biochemical study of type III iodothyronine deiodinase. In Thyroid hormone metabolism: molecular biology and alternative pathways. S.-Y. Wu and T. J. Visser, editors. CRC Press. Ann Arbor, MI. $45-66$.

13. Mortimer, R.H., Galligan, J.P., Cannell, G.R., Addison, R.S., and Roberts, M.S. 1996. Maternal to fetal thyroxine transmission in the human term placenta is limited by inner ring deiodination. J. Clin. Endocrinol. Metab. 81:2247-2249.

14. Venable, J.H. 1939. Intra-uterine bleeding in the pregnant albino rat. Anat. Rec. 74:273-295

15. Becker, K.B., Stephens, K.C., Davey, J.C., Schneider, M.J., and Galton, V.A. 1997. The type 2 and type 3 iodothyronine deiodinases play important roles in coordinating development in Rana catesbeiana tadpoles. Endocrinology. 138:2989-2997.

16. St. Germain, D.L., and Croteau, W. 1989. Expression of phenolic and tyrosyl ring iodothyronine deiodinases in Xenopus laevis oocytes is dependent on the tissue source of injected poly(A)+ RNA. Mol. Endocrinol. 3:2049-2053.

17. Comings, D.E., and Tack, L.C. 1972. Similarities in the cytoplasmic proteins of different organs and species examined by SDS gel electrophoresis. Exp. Cell Res. 75:73-78.

18. Schneider, M.J., and Galton, V.A. 1991. Regulation of c-erbA $\alpha$ mRNA species in tadpole erythrocytes by thyroid hormone. Mol. Endocrinol. 5:201-208.

19. Croteau, W., Whittemore, S.L., Schneider, M.J., and St. Germain, D.L. 1995. Cloning and expression of a cDNA for a mammalian type III iodothyronine deiodinase. J. Biol. Chem. 270:16569-16575.

20. Welsh, A.O., and Enders, A.C. 1983. Occlusion and reformation of the rat uterine lumen during pregnancy. Am. J. Anat. 167:463-477.

21. Snell, G.D. 1941. The early embryology of the mouse. In Biology of the laboratory mouse. G.D. Snell, editor. Dover Publications. New York, NY. 1-54.

22. Roti, E., Fang, S., Braverman, L.E., and Emerson, C.H. 1982. Rat placenta is an active site of inner ring deiodination of thyroxine and $3,3^{\prime}, 5^{\prime}$-triiodothyronine. Endocrinology. 110:34-37.

23. Roti, E., Braverman, L.E., Fang, S., Alex, S., and Emerson, C.E. 1982. Ontogenesis and placental inner ring thyroxine deiodinase and amniotic fluid $3,3^{\prime}, 5^{\prime}$-triiodothyronine concentration in the rat. Endocrinology. 111:959-963.

24. Cooper, E., Gibbens, M., Thomas, C.R., Lowy, C., and Burke, C.W. 1983. Conversion of thyroxine to $3,3^{\prime}, 5^{\prime}$-triiodothyronine in the guinea pig placenta: in vivo studies. Endocrinology. 112:1808-1815.

25. Koopdonk-Kool, J.M., et al. 1996. Type II and type III deiodinase activity in human placenta as a function of gestational age. J. Clin. Endocrinol. Metab. 81:2154-2158.

26. Huang, T., Beredo, A., Solomon, D.H., and Chopra, I.J. 1986. The inner ring (5-) monodeiodination of thyroxine (T4) in cerebral cortex during fetal, neonatal, and adult life. Metabolism. 35:272-277.

27. Huang, T., Chopra, I.J., Boado, R., Solomon, D.H., and Chua Teco, G.N. 1988. Thyroxine inner ring monodeiodinating activity in fetal tissues of the rat. Pediatr. Res. 23:196-199.

28. Galton, V.A., McCarthy, P.T., and St. Germain, D.L. 1991. The ontogeny of iodothyronine deiodinase systems in the liver and intestine of the rat. Endocrinology. 128:1717-1722.

29. Bates, J.M., St. Germain, D.L., and Galton, V.A. 1999. Expression profiles of the three iodothyronine deiodinases, D1, D2 and D3, in the developing rat. Endocrinology. 140:844-851.

30. Chizzonite, R.A., and Zak, R. 1984. Regulation of myosin isoenzyme composition in fetal and neonatal rat ventricle by endogenous thyroid hormones. J. Biol. Chem. 259:12628-12632.

31. Heron, M.I., and Rakusan, K. 1996. Short- and long-term effects of neonatal hypo- and hyperthyroidism on coronary arterioles in rat. Am. J. Physiol. 271:H1746-H1754.

32. Freeman, S., and Sohmer, H. 1995. Effect of thyroxine on the development of somatosensory and visual evoked potentials in the rat. J. Neurol. Sci. 128:143-150.

33. Vogt, M.B., and Rudy, J.W. 1986. Neonatal hyperthyroidism in the rat: thyroxine accelerates the development of unconditioned but not learned responses to tastes. Behav. Neural Biol. 46:358-371.

34. Hebert, R., and Dussault, J.H. 1984. Permanent peripheral hearing system alteration following transient neonatal hyperthyroidism in rats. Brain Res. 316:159-164.

35. Cooke, P.S., Zhao, Y.D., and Bunick, D. 1994. Triiodothyronine inhibits proliferation and stimulates differentiation of cultured neonatal Sertoli cells: possible mechanism for increased adult testis weight and sperm production induced by neonatal goitrogen treatment. Biol. Reprod. 51:1000-1005

36. deMello, D.E., Heyman, S., Govindarajan, R., Sosenko, I.R., and Devaskar, U.P. 1994. Delayed ultrastructural lung maturation in the fetal and newborn hypothyroid (Hyt/Hyt) mouse. Pediatr. Res. 36:380-386 
37. Shafrir, E., Barash, V., Zederman, R., Kissilevitz, R., and Diamant, Y.Z. 1994. Modulation of fetal and placental metabolic pathways in response to maternal thyroid and glucocorticoid hormone excess. Isr. J. Med. Sci. 30:32-41

38. Akita, S., Hirano, A., and Fujii, T. 1996. Identification of IGF-I in the calvarial suture of young rats: histochemical analysis of the cranial sagittal sutures in a hyperthyroid rat model. Plast. Reconstr. Surg. 97:1-12.

39. Hanley, K., Rassner, U., Elias, P.M., Williams, M.L., and Feingold, K.R. 1996. Epidermal barrier ontogenesis: maturation in serum-free media and acceleration by glucocorticoids and thyroid hormone but not selected growth factors. J. Invest. Dermatol. 106:404-411.

40. Hanley, K., Jiang, Y., Katagiri, C., Feingold, K.R., and Williams, M.L. 1997. Epidermal steroid sulfatase and cholesterol sulfotransferase are regulated during late gestation in the fetal rat. J. Invest. Dermatol. 108:871-875.

41. d'Albis, A., et al. 1987. Regulation by thyroid hormones of terminal differentiation in the skeletal dorsal muscle. Dev. Biol. 123:25-32.

42. Rubinstein, N.A., Lyons, G.E., and Kelly, A.M. 1988. Hormonal control of myosin heavy chain genes during development of skeletal muscles. Ciba Found. Symp. 138:35-51.

43. Legrand, J. 1984. Effects of thyroid hormones on central nervous system development. In Neurobehavioral teratology. J. Yanai, editor. Elsevier Science Publishers. New York, NY. 331-363.

44. Bartolome, J., Lau, C., and Slotkin, T.A. 1982. Neonatal hyperthyroidism causes premature development of baroreceptor-mediated cardiac sympathetic reflexes. Dev. Neurosci. 5:208-215.

45. Schwartz, H.L., Ross, M.E., and Oppenheimer, J.H. 1997. Lack of effect of thyroid hormone on late fetal rat brain development. Endocrinology. 139:3119-3124.

46. Narayanan, C.H., and Narayanan, Y. 1985. Cell formation in the motor nucleus and mesencephalic nucleus of the trigeminal nerve of rats made hypothyroid by propylthiouracil. Exp. Brain Res. 59:257-266.

47. Altman, J., and Bayer, S.A. 1982. Development of the cranial nerve ganglia and related nuclei in the rat. Adv. Anat. Embryol. Cell Biol. 74:1-89.

48. Kraft, J.C., Willhite, C.C., and Juchau, M.R. 1994. Embryogenesis in cultured whole rat embryos after combined exposures to 3, 3',5-triiodo-Lthyronine (T3) plus all-trans-retinoic acid and to T3 plus 9-cis-retinoic acid. J. Craniofac. Genet. Dev. Biol. 14:75-86.

49. Bradley, D.J., Towle, H.C., and Young, W.S. 1992. Spatial and temporal expression of $\alpha$ - and $\beta$-thyroid hormone receptor mRNAs, including the $\beta 2$-subtype, in the developing mammalian nervous system. J. Neurosci. 12:2286-2302.

50. Nagasawa, T., Suzuki, S., Takeda, T., and DeGroot, L.J. 1997. Thyroid hormone receptor $\beta 1$ expression in developing mouse limbs and face. Endocrinology. 138:1276-1281.

51. Versloot, P.M., Gerritsen, J., Boogerd, L., Schröder-van der Elst, J.P., and van der Heide, D. 1994. Thyroxine and 3,5,3'-triiodothyronine production, metabolism, and distribution in the pregnant rat near term. Am.J. Physiol. 267:E860-E867.

52. Glinoer, D. 1997. The regulation of thyroid function in pregnancy: pathways of endocrine adaptation from physiology to pathology. Endocr. Rev. 18:404-433.

53. Escobar-Morreale, H., Obregón, M.J., Escobar del Rey, F., and Morreale de Escobar, G. 1995. Replacement therapy for hypothyroidism with thyroxine alone does not ensure euthyroidism in all tissues, as studied in thyroidectomized rats. J. Clin. Invest. 96:2828-2838.

54. Escobar-Morreale, H., Escobar del Rey, F., Obregón, M.J., and Morreale de Escobar, G. 1996. Only the combined treatment with thyroxine and triiodothyronine ensures euthyroidism in all tissues of the thyroidec- tomized rat. Endocrinology. 137:2490-2502.

55. Abrahamsohn, P.A., and Zorn, T.M.T. 1993. Implantation and decidualization in rodents. J. Exp. Zool. 266:603-628.

56. Robb, L., et al. 1998. Infertility in female mice lacking the receptor for interleukin 11 is due to a defective uterine response to implantation. Nat. Med. 4:303-308.

57. Bilinski, P., Roopenian, D., and Gossler, A. 1998. Maternal IL-11R alpha function is required for normal decidua and fetoplacental development in mice. Genes Dev. 12:2234-2243.

58. Finn, C.A. 1971. The biology of decidual cells. Adv. Reprod. Physiol. 5:1-26.

59. Starkey, P.M. 1993. The decidua and factors controlling placentation. In The buman placenta. C.W.G. Redman, I.L. Sargent, and P.M. Starkey, editors. Blackwell Scientific Publications. Boston, MA. 362-413.

60. Remacle, J., Michiels, C., and Raes, M. 1992. The importance of antioxidant enzymes in cellular aging and degeneration. EXS. 62:99-108.

61. Black, S.M., and Wolf, C.R. 1991. The role of glutathione-dependent enzymes in drug resistance. J. Clin. Pharm. Ther. 51:139-154.

62. Gray, B., and Galton, V.A. 1974. The transplacental passage of thyroxine and foetal thyroid function in the rat. Acta Endocrinol. 75:725-733.

63. Morreale de Escobar, G., Calvo, R., Obregón, M.J., and Escobar del Rey, F. 1990. Contribution of maternal thyroxine to fetal thyroxine pools in normal rats near term. Endocrinology. 126:2765-2767.

64. Vulsma, T., Gons, M.H., and de Vijlder, J.J.M. 1989. Maternal-fetal transfer of thyroxine in congenital hypothyroidism due to a total organification defect or thyroid agenesis. N. Engl. J. Med. 321:13-16.

65. Morreale de Escobar, G., Obregón, M.J., Calvo, R., and Escobar del Rey, F. 1993. Effects of iodine deficiency on thyroid hormone metabolism and the brain in fetal rats: the role of the maternal transfer of thyroxin. Am. J. Clin. Nutr. 57:280S-285S.

66. Obregón, M.J., Mallol, J., Pastor, R., Morreale de Escobar, G., and Escobar del Rey, F. 1984. L-thyroxine and 3,5,3'-triiodo-L-thyronine in rat embryos before the onset of fetal thyroid function. Endocrinology. 114:305-308

67. Contempré, B., et al. 1993. Detection of thyroid hormones in human embryonic cavities during the first trimester of pregnancy. J. Clin. Endocrinol. Metab. 77:1719-1722.

68. Velardo, J.T., Dawson, A.B., Olsen, A.G., and Hisaw, F.L. 1953. Sequence of histologic changes in the uterus and vagina of the rat during prolongation of pseudopregnancy associated with the presence of deciduomata. Am. J. Anat. 93:273-305.

69. Esfandiari, A., et al. 1994. Induction of type III-deiodinase activity in astroglial cells by retinoids. Glia. 11:255-261.

70. Esfandiari, A., Courtin, F., Lennon, A.M., Gavaret, J.M., and Pierre, M. 1992. Induction of type III deiodinase activity in astroglial cells by thyroid hormones. Endocrinology. 131:1682-1688.

71. Courtin, F., Liva, P., Gavaret, J.M., Toru-Delbauffe, D., and Pierre, M. 1991. Induction of 5-deiodinase activity in astroglial cells by $12-\mathrm{O}-$ tetradecanoylphorbol 13-acetate and fibroblast growth factors. J. Neurochem. 56:1107-1113

72. Hernández, A., and Obregón, M.J. 1995. Presence of growth factorsinduced type III iodothyronine 5-deiodinase in cultured rat brown adipocytes. Endocrinology. 136:4543-4550.

73. Hernández, A., St. Germain, D.L., and Obregón, M.J. 1998. Transcriptional activation of type III inner ring deiodinase by growth factors in cultured rat brown adipocytes. Endocrinology. 139:634-639.

74. Mossman, H.W. 1937. Comparative morphogenesis of the fetal membranes and accessory uterine structures. In Contributions to embryology. No. 158., vol. 479. Carnegie Institution of Washington. Baltimore, MD. 221. 